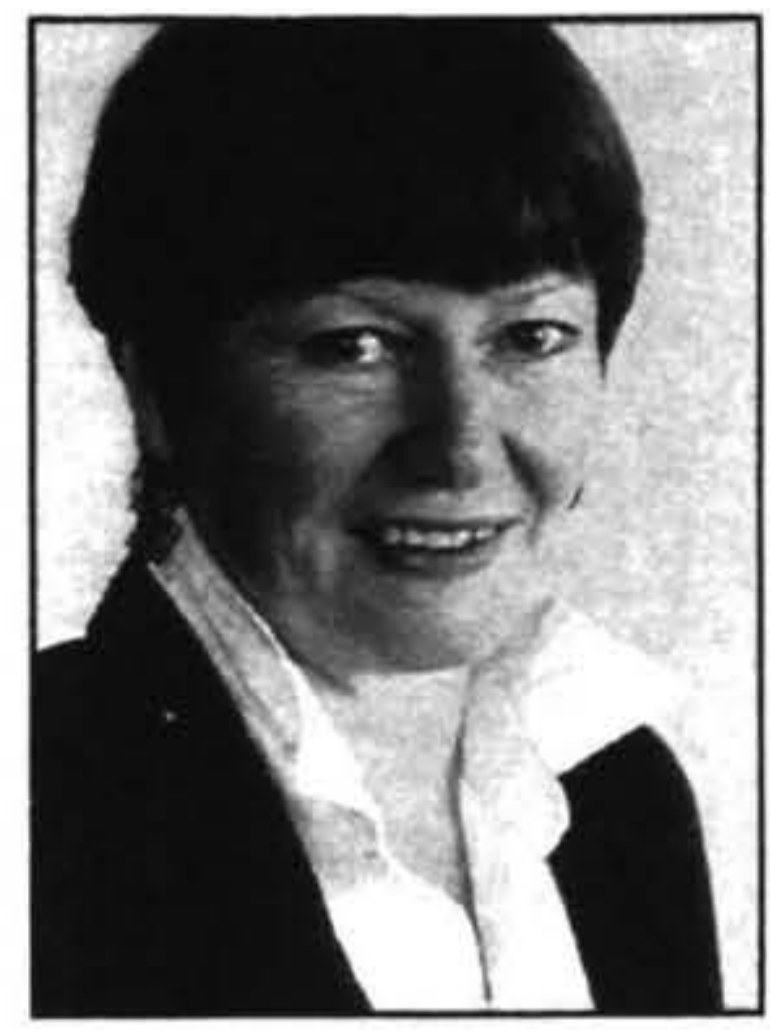

\title{
PAID WORK AND INTELLECTUAL DISABILITY
}

\author{
Pat Reid \\ School of Continuing Education \\ Nelson Polytechnic
}

\begin{abstract}
Adults with intellectual disabilities in paid work have voiced a number of concerns regarding their employment: independence at work, the continued need for links with formal support, choices in lifestyle opportunities and lack of career path options. In a central New Zealand region selected agencies were asked to identify adults with intellectual disabilities who had paid work. The agencies then forwarded invitations to adults whom they considered were successfuly employed. Seventeen workers responded and were interviewed on how they obtained and learned their job and the initial and on-going support they received. If permissions were gained from both parties then important other persons $/ s$ were also interviewed. As a result of this survey strategies leading to better opportunities and greater employment rates for adults with intellectual disabilities are offered.
\end{abstract}

This paper reports on a research project completed in a central New Zealand region, funded by Foundation for Research, Science and Technology, and jointly completed by myself and Dr Anne Bray of the Donald Beasley Institute in Dunedin. The research sought the opinions of paid workers with intellectual disabilities, supporters and employers, and looked for strategies for greater employment rates, and for information that would lead to better decision-making by education, training, and support agencies.

On a global scale, the social responsibility of business has followed several paths. In some countries, for example, Germany, businesses are required by law to employ a certain number of workers with disabilities. In New Zealand however, this is model is discretionery. Here we have a variety of topics which relate to employing workers with disabilities, including employment rates, training for work, ACC and rehabilitation, natural supports, and supported employment. (Bennie, 1996; Department of Social Welfare, 1990; New Zealand Official Yearbook 1996, 1996; Prime Ministerial Taskforce on Employment. 1994; Reid \& Bray, 1996 a\&b; Reid \& Hitchcock, 1996; Smith, 1991; State Services Commission, 1994; Wilson, 1996).

Supported employment is a set of strategies which aim to get and keep people in paid work. Historically, it grew out of the United States of America where it related to people with usually severe intellectual disabilities. Currently in New Zealand, supported employment focuses on discovering preferences, skills and needs of people with disabilities who want work, very precise matching of workers to jobs, and promotes career development and choices (Bennie, 1996, p3). The support comes in the form of paid professionals who have (or should have) extensive knowledge of employ- ment law and regulations, who can match workers to positions and provide the necessary support to workers and employers, and who have the skills and networks to access on employment chances.

Some people with disabilities need someone to help with an application, some people need to use someone elses networks and knowledge of the job market to help them find a suitable job, some people need someone to help them negotiate a workplace modification or on-the-job training, and some people need help with wage subsidies and the Income Support interface. For some people, this support is a one-off effort, and for others, on-going support is needed to ensure that worker and employer have a valued relationship. Supported employment covers a range of skills and efforts.

Our research focused on the experiences of paid workers with intellectual disabilities. Traditionally, people with intellectual disabilities have been excluded from paid work.

Past practices of hospitalisation have meant that the worker status of people with intellectual disabilities has not been publically recognised. In an earlier research effort which focused on older adults with intellectual disabilities, we heard how some people, particularly during the war years, were employed in the open paid workforce. In hospitals, a high value was attached to work and workers, if paid, often received cigarettes. At one large hospital, the hospital farm operated economically because of the large contribution made by the male patients (Williams, 1987). But generally, the worker status of people with intellectual disabilities has not been widely recognised, either in institutions or communities. 
As a result of changing philosophies and strong parent advocacy, people with intellectual disability now live and learn in our communities. Officially, however, they are highly likely to receive state-provided income support and unlikely to be registered as unemployed, that is, actively seeking and available to work. Clearly, paid work has not yet established itself as the logical conclusion to living in the community.

\section{Who were the workers?}

We audio-taped and transcribed interviews with fourteen workers labelled as having intellectual disabilities. The youngest person was 24 years of age, the oldest was in his early forties, and there were eight men and six women. Two people lived with parents, three people flatted in homes owned privately and the others lived in homes supervised by IHC- New Zealand Society for the Intellectually Handicapped Inc.

Most workers interviewed had part-time work, constant hours, and were officially categorised as having elementary occupations in the community, social and personal services sector of the workforce. Six people (see Table 1) had cleaning work. They cleaned either cars, private dwellings, public facilities or a tourist lodge. Caretaking $(n=2)$ often included cleaning chores, especially on wet days when outside work was not possible.

\section{Table 1. Type of work $(n=14)$}

\begin{tabular}{lc}
\hline Type & $\mathrm{n}$ \\
\hline Cleaning & 6 \\
Caretaking & 2 \\
Processing primary produce & 2 \\
Labouring & 1 \\
Assisting at library & 1 \\
Assembling products & 1 \\
Delivering goods & 1 \\
\hline TOTAL & 14 \\
\hline
\end{tabular}

Five people (see Table 2) worked full-time, that is, 30 plus hours per week with three workers, all males, working a 40 hour week. The other nine people worked part-time (less than 30 hours per week), and hours were spread across several days, rather than a few days with many hours per day. Five workers worked less than ten hours per week with two of these people, both women, working minimal hours.

\section{Table 2. Hours per week in main job and gender $(n=14)$}

\begin{tabular}{llll}
\hline & Male & Female & Total \\
\hline $1-4$ & - & 2 & 2 \\
$5-9$ & 2 & 1 & 3 \\
$10-19$ & 1 & 1 & 2 \\
$20-29$ & 2 & - & 2 \\
30 plus & 3 & 2 & 5 \\
\hline TOTAL & 8 & 6 & 14 \\
\hline
\end{tabular}

Eight people had constant supervision while they worked and six worked independently, often with no one else around. Half the group dealt with the public as part of their job.

\section{Who were the employers?}

Nationally, $74 \%$ of all employees work in private enterprises, $26 \%$ for public departments or government. In this project, no one was identified who worked for public departments or government although several people were known to have worked for the government prior to restructuring and cost cutting efforts. All fourteen workers were employed by private enterprises. In terms of size of business employing the workers in the study group, over half worked in quite small businesses, that is, less than 5 FTEs.

\section{Workers perspectives}

The majority of workers had very clear views about the purpose of work, what was expected of them and what they expected from work. " "... no money, no nothing. Nothing to do." This woman explained that if she could not work, she would have nothing to live on. Seven workers said that it was the money they worked for. Only two people nolonger received a benefit, but several others aimed to be in such a situation, or at least to have more work and in turn, more money. One man currently worked 20 hours per week but still " ... I'd prefer to be without the benefit really. Um I know its going to be very hard but its not easy for some people who's on disability ..."

Most workers recognised that some of their wages contributed to daily living expenses as well as things they liked to do or have, such as music tapes, clothes and going to social events. Others saved for larger purchases such as their own home, a holiday, stereo, motorbike or car.

Four workers had other reasons why they worked. One man said it was to fill in time and two people said they worked because they enjoyed what they did. One worker said her job was "... interesting ..." and another worker mentioned she was learning new things that interested her and that might lead to a better job. Two people mentioned that as well as the money, their work enabled them to keep fit.

Most workers recalled previous work opportunities. Six people had previously worked in other jobs in the open workforce and one woman, who had once lived in hospital, had an extensive history of both paid and unpaid work. All the others had some kind of work experience including working on special work schemes, either at sheltered workshops, home base or in satellite teams. One man explained that he had been paid for odd jobs in the past, but got - "... very little. Um its how the benefit works ..."

\section{Work ethic}

Workers were asked why they thought they got the job ahead of other people. One worker replied, "Well because I was committed, I was prepared to give it a go and I wanted to work". Such sentiments were re-iterated by several workers. 
One person said that she was selected for a particular job because she "... could be motivated to do it and be independent and do it by myself". She was very clear that some of the responsibility of getting work rested with the people themselves.

They should be getting up and doing, getting out, getting staff to help them find jobs out in the community instead of sitting around and doing nothing. They could be doing more for theirselves, get staff to find their jobs, look in papers and find what jobs are here around in this area and get motivated.

This comment also highlights the need mentioned by most workers for someone to help them find work. It was support staff not newspapers or notice boards that produced jobs. On the one occasion a worker reported that his family had found him a job, but he found out later that it was in fact a volunteer position. He was hurt that his family presumed he would not get paid.

Several workers were well aware of the investment that they needed to make to be a successful worker. Workers said "... you've gotta be hard, you've got to stick to these jobs, you just can't get up and leave the next day ..." and, "...I've been working so well in keeping up throughout the day without leaving anything ... without making mistakes or anything." One man was very clear he would stick to his job because "... A lot of people out of jobs, people without jobs, thousands."

One woman completed two years voluntary work in the hope that this investment, "..a foot in the door ...", would get a job. The two years of volunteer work paid off, and a job, on a year by year contract, was offered. One man said "I've done awful jobs in my time ... so sometimes I think they should give it a go, I mean if it doesn't work out well then you've got nothing to lose, at least you've had a try."

\section{Career paths}

Several workers identified additional work that they would like to do. Five workers who had part-time job/s, felt they were capable of more or other work, and hoped that something else would eventuate. One man acknowledged it would be very hard, but that he would prefer to be off the benefit. Another said he was not very proud of his current job because it would not mean a full-time job. "I'd like to get a full-time job".

One woman recalled numerous housecleaning jobs she once had but over the years, the number of families she worked for had decreased and she now had very little paid work. She knew such work was likely to exist but could not access it of her own accord. It was very clear that she wanted more paid work.

Three workers suggested that they would like a change in work. They had both successfully learned and completed their jobs and were paid a regular wage. One worker suggested that she could cope with a similar job at a different venue and had thought about moving. The other worker was hopeful of a promotion (which eventuated after the interview was completed). The third person could see that if she learned and worked well, then further opportunities were possible and she intended to get ahead.

On the other hand, a few workers knew of tasks that they could not do. For example, not using a weed eater, chainsaw or ride-on mower were mentioned. One worker said about the weed eater "I felt very scared, very nervous in case that I might cut my feet off or my toes". One woman said she was offered the chance to learn other tasks- "... but I wouldn't do that, it was too hard, couldn't cope with that either." One man described how he had become redundant three years ago when new processing systems were introduced "...but the work got a bit complicated and the bosses weren't prepared to have a go at work that I felt I couldn't do." His comment supports the theme of workers recognising that there were tasks they could not do limitations and not wanting to do badly. One woman, speaking generally, said that it would be very hard for some people whom she knew at IHC to get jobs. She knew of people based in a workshop on a commercial site and said they did not have real jobs. In her opinion, not everyone would be able to have a real job like hers.

\section{Social opportunities}

Five of the fourteen people worked with no one else around. They did not meet anyone else except in passing and so did not meet new people or have the opportunity to make friends. In addition, one woman, although she worked alongside others, arrived during a tea break and left the premises at lunch time so no socialising was possible.

In contrast, all the other workers were able to socialise with other workers at some stage of the working day. Six workers had constant contact with other people as they worked and some workers had dealings with the public. One woman, who works in a library, said she sees "... quite alot of people from [local resthome] and they come in and I sometimes help them chose books if they want books and that..." Two workers wore ear muffs, so although they were part of a team, socialising was only possible during tea/coffee breaks. One man, when asked how hard it was to make friends when he first got his job, said it was not hard at all as many of the existing workers had been at school with him.

Only one person occasionally visited, and received visits from, a work colleague outside of work hours. All other workers either maintained the friends they already had, or went to social or recreational events of their choice. Such activities included a running club, fishing, outdoor bowls and two different community service clubs. One man said that his work "happy hour" was on the same night as a social function organised by a community homes support group. He chose (and paid his own transport) to go to the non-work function where he saw people he had known for a long time. Another person said he sometimes went to the weekly work function. One woman said she did not see the people from her work anywhere else, and that she was at home in the 
weekends, "I need my rest...". She attended all formal work functions and spoke proudly of receiving a gift, along with the others, at Christmas time.

Work is generally expected to fulfil a variety of social functions (Prime Ministerial Taskforce on Employment, 1994). For the workers in this study, the expected social opportunities were often not possible because work was completed in the absence of other workers. And often if there were other workers nearby, the part-time nature of the job restricted the amount of socialising to short breaks. If workers had both work and non -work related social opportunities, they preferred to attend non-work related functions and continued long-term friendships or pursued selected activities. The general expectation that paid work would fulfil a variety of social functions had not eventuated.

\section{Major lifestyle changes}

It was apparent that paid work had resulted in major life changes for some people. Two people, both men, no longer received any income support from the state. Three people had, or were close to buyingtheir own home, and as mentioned earlier, several people were repaying loans that had been used to buy major items. Two people had to learn the public transport system in order to get to and/or from work. One man explained that travelling on the bus "....wasn't so easy for a person who's [got a] disability..." because sometimes the bus went right past him at the bus stop and on several occasions he had to walk home. The other worker had learned to get home on the bus after work. Later she used this knowledge to get to a polytechnic course she was doing. Four people owned (were repaying loans for) cars, motorbikes or motorscooters. They had had several attempts at gaining drivers' licenses with questions being read out, rather than completing a written test.

\section{Sources of support}

Family played an important role in the lives of five people. Two families had assisted with the purchase of houses that the workers now lived in and paid for via a mortgage. Both families arranged community support agencies to provide on-going help within the houses. One mother had to help her daughter when issues surrounding the benefit became complicated. The worker explained that "...I'm meant to be on secondary [tax] because I still get my benefit and it kept on mucking [employer] up and I kept on ringing them up, and mum ... luckily enough it'sorted out". The worker had tried to sort out her pay issues, but had needed help.

One woman said her mother sometimes visited her during work hours. When asked if she felt it was a visit to see her as a worker or a daughter, the woman said "I am actually the worker". One father totally managed his daughter's finances and she seemed to have no say in what happened to her earnings. Only two people lived at home and workers' contacts with family were oriented to social rather than employee related issues or activities.

If an issue related to work, workers would seldom go to family if they needed help. Workers had several strategies for coping with any work related problems that arose. Most workers named support staff they would go to if they had a problem. This staff person was often someone that had helped in getting or learning the job. One worker said that he was still under the umbrella of IHC and although he had not needed any help in the past six years, IHC was still very important to him. He liked to keep in touch with a particular staff member at IHC. His family lived nearby but he would not go to them for help. Another worker emphasised that he had left IHC and was no longer a member. He said when he started work, he very much missed some of his friends but now he had made new ones. He also kept in touch with a particular staff member from IHC. He had family who lived nearby but would choose to go to the IHC staff person if he needed work related help.

Some workers said that if they had a problem they would go directly to their boss. One man, who lived at home, said "...he really is a lovely boss... he usually helps me out if I've got any problems or I want to talk to him about anything. $\mathrm{He}$ said he'd help me out on any problems and that, just sit down and talk about things..." He clearly, would not seek help from his family even though he lived at home.

\section{Summary}

To sum up, the workers described their efforts to ensure they remained in the paid workforce.

First, they were aware of the need to take the work opportunities that were offered to them and some workers had spent years hoping for a paid work chance.

Second, they were highly motivated to be good employees. A few workers recognised tasks they could not complete and described how those tasks were completed by others. Otherwise, workers were expected to complete tasks to the same standard as other employees. Although part-time work was usual, several felt they were capable of more work and hoped that more hours, another job and getting off the benefit would eventuate. One worker said he was not very proud of his current job because it would never lead him to a full-time job and the chance to be off the benefit.

Third, various sources of support were named by workers. Families were not usually mentioned in connection to jobs because workers elected to refer work related problems or issues to particular support staff that were, or had been, associated to early stages of their careers. Formal support staff were important for finding paid work opportunities as well as being available at any later stage if work related problems or issues arose. They do not want to be filed after a job is found for them. It was clear that their reasons for and motivation to work mirrors that of the general population. They wanted to earn a living, valued their jobs, wanted the chance to progress to more hours or greater challenges- real pay for real jobs. 


\section{Future research}

Based on our research, we suggest three areas that need investigation.

First at an official level, there needs to be an immediate evaluation of how current funding for employment services for this population is actually being used. Officially, people with intellectual disabilities are highly likely to receive state-provided income support and unlikely to be registered as unemployed, that is, actively seeking and available to work. However, most people with intellectual disabilities are not 'unemployable'. This study supports the need for urgent re-examination of assumptions about who is employable. An evaluation of the funding an operation of generic and special employment services for people with intellectual disabilities is essential if possibilities for greater economic self-sufficiency and well being for this population are to be relalised in thefuture.

Second, people with intellectual disabilities themselves must identify specific outcomes of their employment. For example, the general expectation that work would lead to increased social opportunities did not eventuate and this finding could only be described via the workers' perspectives. It must be expected that their perspectives may challenge existing assumptions about the goals of work. Future research will need to enable unexpected views to surface.

Third, employers' perspectives were not fully explored in our work because the workers had control over who was interviewed about them and few workers gave permission for this process. Employers' perspectives are clearly essential if paid work for this population is to be a reality for the future. Other research methods will need to be utilised to ask questions which only meployers can answer, such as why a staff member was employed, what training was needed, what on-going support was required and what, if any, costs were incurred.

\section{References}

Bennie, G. 1996 Critical Issues for Supported Employment in New Zealand. In G. Bennie (Ed.), Supported employment in New Zealand: getting the job done. (ppl-9). Levin: Network Publications.

Prime Ministerial Taskforce on Employment. 1994 Employment:The Issues. Wellington.

Reid, P. M. \& Bray, A. 1996 Paid work and intellectual disability. Australia and New Zealand Journal of Developmental Disabilities. (Submitted for publication).

Reid, P. \& Bray, A. 1996 Real jobs: The perspectives of workers with intellectual disabilities. Disability and society. (submitted for publication).

Reid, P. \& Hitchcock, J. 1996 Continuing Education and Intellectual Disability. In G. Bennie (Ed.) Sup- ported employment in New Zealand: getting the job done. (pp 48-60). Levin: Network Publications.

Smith, V. 1991 Some economic issues affecting public policy on disability. New Zealand Journal of Industrial Relations. 16: 273-280.

State Services Commission. 1994 Mainstreaming support: a guide for potential employers of the mainstream supported employment programme. State Services Commission, Wellington.

Wilson R. 1996 Return to work- The New Zealand experience under the Accident Compensation scheme. New Zealand Journal of Industrial Relations, 21(2):171-177

Williams, H. 1987 Out of mind, out of sight. Poirirua Hospital, Poirirua.

\section{Author}

Pat Reid is a Researcher in the School of Continuing Education, Nelson Polytechnic,Private Bag 19, Nelson. Email preid@admin.nelpoly.ac.nz 